\section{Phytophthora Root Rot Resistance and Its Correlation with Fruit Rot Resistance in Capsicum annuum}

\author{
Rachel P. Naegele \\ San Joaquin Valley Agricultural Sciences Center, U.S. Department of \\ Agriculture, Agriculture Research Service, Parlier, CA 93648 \\ Mary K. Hausbeck \\ Department of Plant, Soil and Microbial Sciences, Michigan State \\ University, East Lansing, MI 48824
}

\begin{abstract}
Phytophthora capsici causes root and fruit rot and foliar blight of pepper. Multiple sources of resistance to Phytophthora root rot have previously been identified, but most display only partial resistance. One source, CM334, has broad spectrum root rot resistance to multiple pathogen isolates but has only low to moderate fruit rot resistance. This study evaluated previously identified pepper lines for resistance to two $P$. capsici isolates, OP97 and 12889, and compared root rot resistance to fruit rot resistance and genetic structure. CM334 was confirmed as a broad spectrum resistance genotype, whereas all other sources of resistance evaluated were susceptible to infection by one or both isolates evaluated. Although not completely resistant, PI 566811 displayed moderate resistance to fruit and root rot to both $P$. capsici isolates. Fruit rot resistance had a significant but small to moderate positive correlation $(r=0.26-0.63)$ with root rot resistance depending on the isolate and length of exposure. Pepper accessions with resistance to Phytophthora root and fruit rot belonging to different genetic subpopulations were identified and could serve as candidates for partial-resistance loci to incorporate into pepper breeding programs.
\end{abstract}

Phytophthora capsici Leonian infects a wide range of crop species including ornamental and vegetable solanaceous crops (Enzenbacher et al., 2015; Foster et al., 2012; Naegele et al., 2014). Without effective disease management strategies, the pathogen can cause up to $90 \%$ crop loss with an estimated annual loss of US\$100 million across susceptible crops (Granke et al., 2012b). To minimize the risk associated with producing $P$. capsici-susceptible crops, researchers have focused on pathogen epidemiology, fungicide, and cultural strategies to understand pathogen dispersal and develop effective management practices that include rotations of drip-applied fungicides and cultivars with reduced susceptibility (Gilardi et al., 2013; Granke et al., 2012b; Parada-Rojas and Quesada-Ocampo, 2019).

Host resistance to diverse isolates of $P$. capsici is an important management tactic and a focus for pepper (Capsicum annuum) breeding programs globally. In pepper, the pathogen can cause root rot, foliar blight, and

Received for publication 17 Aug. 2020. Accepted for publication 21 Sept. 2020.

Published online 17 November 2020.

We thank Abigail Tomlinson, Samantha Boyle, Jonathan Kurjan, and Jenna Mitchell for technical assistance.

R.P.N. is the corresponding author. E-mail: rachel. naegele@ars.usda.gov.

This is an open access article distributed under the CC BY-NC-ND license (https://creativecommons. org/licenses/by-nc-nd/4.0/). resistance and $P$. capsici isolates, has been observed. This is true for root and fruit rot resistance and foliar blight resistance in pepper (Candole, 2012; Glosier et al., 2008; Naegele et al., 2013, 2014; Sy et al., 2005).

When $\approx 2300$ pepper lines were screened, nearly 80 accessions with some level of resistance to Phytophthora root rot were identified (Candole et al., 2010). Despite the many studies evaluating root rot resistance in pepper, including multiple landraces evaluated from Mexico, only one landrace has been consistently resistant to $P$. capsici. CM334, widely acknowledged as stable source of $P$. capsici resistance, is used in breeding programs across the globe. Studies have shown that this landrace is resistant to all isolates of $P$. capsici that have been tested to date (Glosier et al., 2008; Oelke et al., 2003; Ortega et al., 1991; Parada-Rojas and
Quesada-Ocampo, 2019; Sy et al., 2008). Capsicum sources of resistance have been identified from Mexico, China, and India (Barksdale, 1984; Candole et al., 2010; Lefebvre and Palloix, 1996; Mallard et al., 2013). Mapping populations derived from some of these sources of resistance have determined that although chromosome 5 is the major locus, there is variation in minor resistance loci (Thabuis et al., 2003). In a study by Thabuis et al. (2003), three sources of resistance including CM334 and PI 201234 had the major locus at chromosome 5 , but also had unique smaller effect loci on chromosomes $3,6,10$, and 12. A better understanding of the genetic diversity and structure of pepper, and its association with Phytophthora-induced diseases, is key to stacking novel sources of resistance.

Few studies have evaluated fruit rot resistance to $P$. capsici in pepper, and fewer have evaluated the relationship between fruit and root rot resistance (Biles, 1993; Foster and Hausbeck, 2010; Saini and Sharma, 1978; Tahboub et al., 2008). Complete resistance to Phytophthora fruit rot in pepper has not been identified in any accession evaluated to date. CM334, although resistant to root rot, exhibited lesions or spotting on fruit when inoculated (Naegele et al., 2013). In CM334, major quantitative trait loci (qtl) for resistance to fruit rot were identified on chromosome 5 , as well as a minor qtl on chromosomes 2 and 4 (Naegele et al., 2013). Phytophthora fruit rot resistance was characterized across 170 pepper lines, and low differentiation was detected among resistant and susceptible subpopulations (Naegele et al., 2014). However, the relationship between Phytophthora fruit and root rot resistance across diverse germplasm is unclear.

The objectives of this project were to evaluate potential sources of resistance to $P$. capsici root rot against two virulent isolates, determine population genetic structure associated with root rot resistance, and evaluate the correlation between root rot and fruit rot resistance in Capsicum.

\section{Materials and Methods}

Plant material and isolates. Eighty $C$. annuum lines and one $C$. frutescens (PI 593920) representing wild, cultivated, and landrace materials from the U.S. Department of Agriculture Germplasm Resource Information Network or commercial seed sources: Johnny's Select Seeds, Parks Seed, and Seedway (http://www.ars-grin.gov/) were evaluated for Phytophthora root rot (Table 1). Twenty seeds from each line were sown into 72-cell trays containing a soilless peat mix (Suremix Michigan Grower Products, Inc., Galesburg, MI) in a polyethylene greenhouse at the Michigan State University (MSU) Horticulture Research Farm (East Lansing, MI). The planted 72-cell trays were placed onto heat pads to maintain a soil temperature of $\approx 26.67{ }^{\circ} \mathrm{C}$, for $\approx 1$ month after planting. Seedlings were transferred to 4 -inch black 
Table 1. Capsicum annuum genotypes evaluated for resistance to Phytophthora root rot resistance.

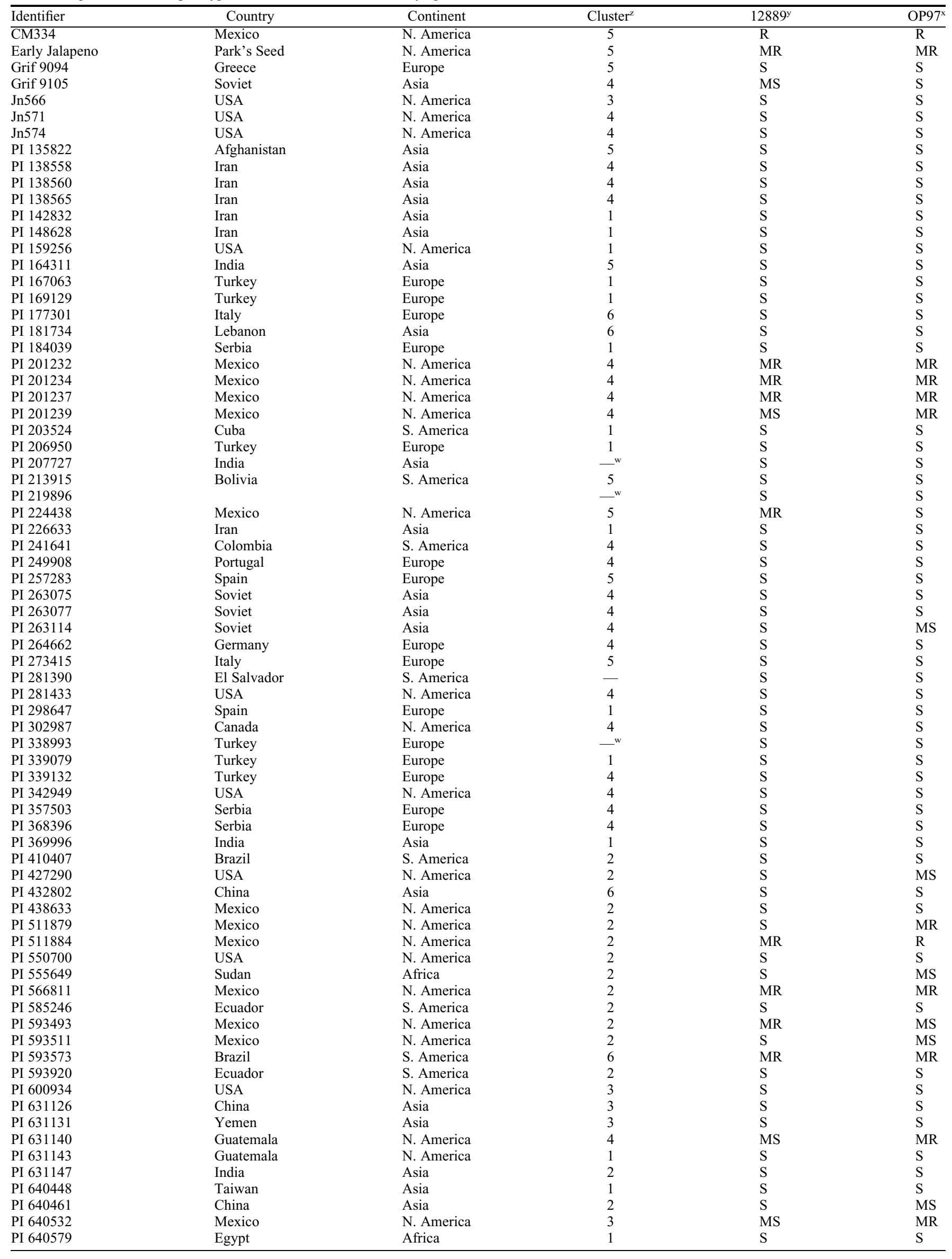


Table 1. (Continued) Capsicum annuum genotypes evaluated for resistance to Phytophthora root rot resistance.

\begin{tabular}{|c|c|c|c|c|c|}
\hline Identifier & Country & Continent & Cluster $^{z}$ & $12889^{y}$ & OP97 $^{x}$ \\
\hline$\overline{\text { PI } 640581}$ & Nigeria & Africa & 2 & $\mathrm{~S}$ & MR \\
\hline PI 640670 & India & Asia & 2 & $\mathrm{~S}$ & $\mathrm{~S}$ \\
\hline PI 640676 & Kenya & Africa & 3 & $\mathrm{~S}$ & $\mathrm{~S}$ \\
\hline PI 640803 & Philippines & Asia & 2 & MS & $\mathrm{R}$ \\
\hline PI 640833 & USA & N. America & 3 & $\mathrm{~S}$ & $\mathrm{R}$ \\
\hline PI 645520 & Italy & Europe & 3 & $\mathrm{~S}$ & $\mathrm{~S}$ \\
\hline PI 653650 & Bangladesh & Asia & 2 & $\mathrm{~S}$ & $\mathrm{~S}$ \\
\hline
\end{tabular}

${ }^{\mathrm{z}}$ Genetic cluster assignment based on STRUCTURE results.

${ }^{\mathrm{y}}$ Disease rating based on the lowest level of resistance to isolate 12889 across two experiments.

${ }^{\mathrm{x}}$ Disease rating based on the lowest level of resistance to isolate OP97 across two experiments.

${ }^{\mathrm{w}}$ Indicates DNA was not available for this accession.

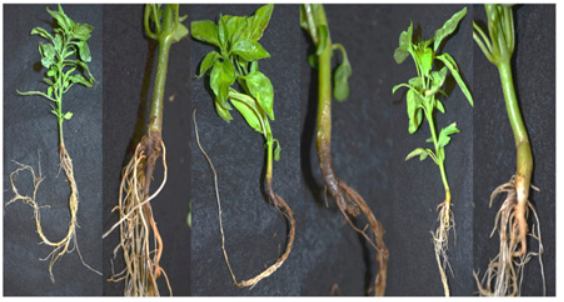

Fig. 1. Root lesion phenotypes observed on plants that survived until the end of the study inoculated with Phytophthora capsici isolate 12889 or OP97.

plastic pots containing the same soilless peat mix before inoculations.

Root rot inoculation and evaluations. Two isolates were selected from the longterm collection of Dr. Mary K. Hausbeck (MSU). Isolates were characterized by host, mefenoxam sensitivity $(\mathrm{I}=$ insensitive, $\mathrm{S}=$ sensitive) and mating type (A1 or A2). Isolate 12889 (pepper, I, A1) and isolate OP97 (cucumber, S, A1) were maintained on unclarified V8 agar (UCV8; $16 \mathrm{~g}$ of agar, $3 \mathrm{~g}$ of $\mathrm{CaCO} 3,160 \mathrm{~mL}$ of $\mathrm{V} 8$ juice, and $840 \mathrm{~mL}$ of distilled water) for the duration of the experiment. Before inoculations, isolates were activated by inoculating and recovering each isolate from a single pepper fruit. Inoculum was prepared by adding sixteen $6-\mathrm{mm}$ plugs of each isolate from an actively growing culture to a 1-L bottle of prepared millet and grown for 2 to 3 weeks at room temperature $\left(21^{\circ} \mathrm{C}\right)$ to allow the pathogen to colonize and distribute throughout the millet as described by Quesada-Ocampo and Hausbeck (2010). Using a falcon tube, $1.5 \mathrm{~g}$ of inoculated millet were applied to the root ball of each plant, covered with soil, and carefully watered to promote infection. Control plants were inoculated with $1.5 \mathrm{~g}$ of sterile millet. Four replicate plants were used for each isolate, with two replicate control plants. Plants were evaluated in batches because not all pepper accessions were ready at the same time. Two accessions, CM334 and Grif 9094, were included as resistant and susceptible checks, respectively, in each batch. Disease was assessed three times at weekly intervals for 8 weeks according to the following scale: $0=$ no wilting, $1=1<25 \%$ wilting, $2=25$ to $<50 \%$ wilting, $3=50$ to $<75 \%$ wilting, $4=75 \%$ to $95 \%$ wilting $5=$ $>95 \%$ wilting or plant death modified from Foster and Hausbeck (2010). Approximately

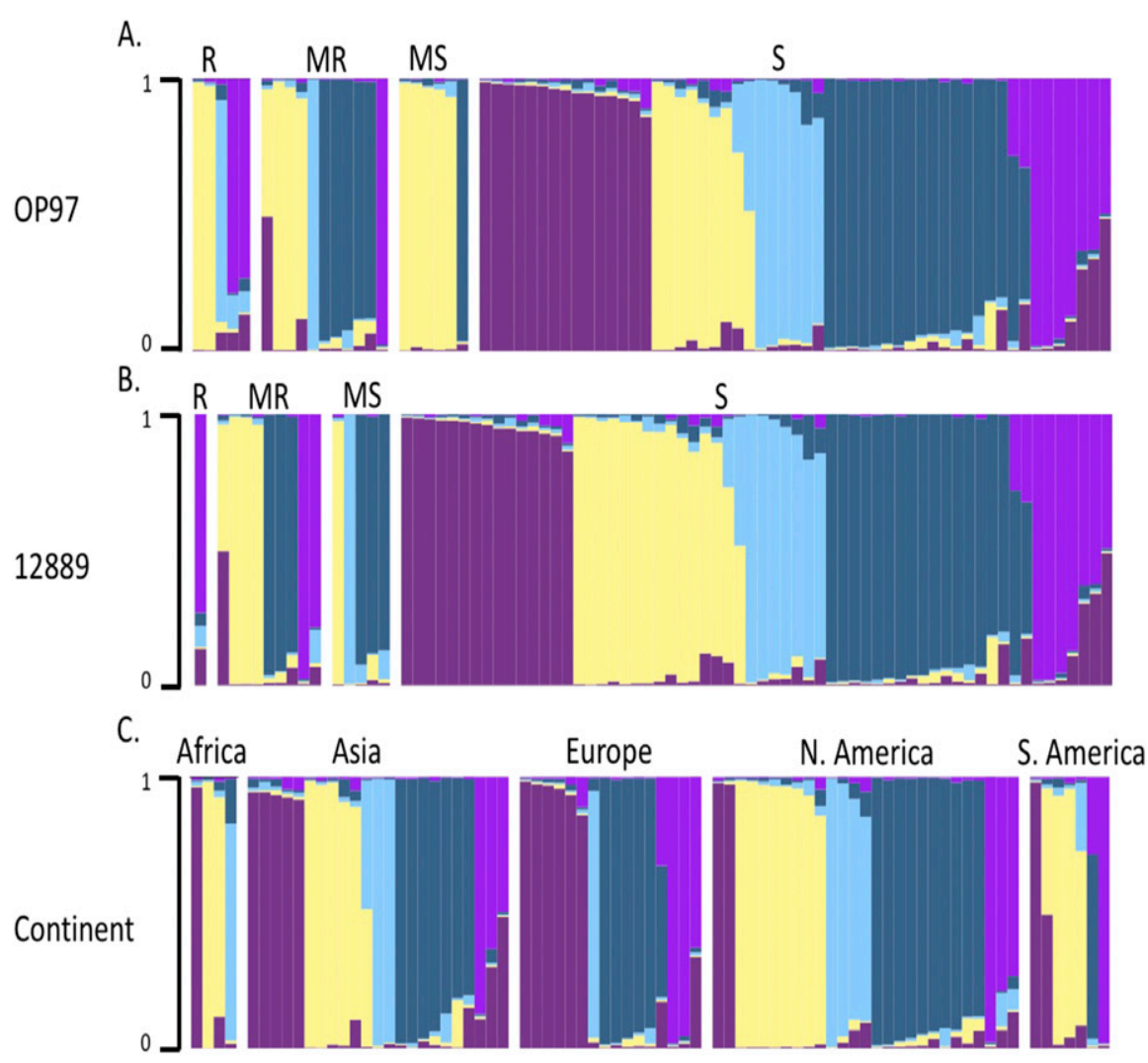

Fig. 2. Pepper germplasm grouped into categories based on disease resistance phenotype to (A) isolate OP97, (B) isolate 12889, or (C) continent of origin. Each bar indicates a unique individual and colors represent identified genetic clusters.

$10 \%$ of plants with a rating of 5 were returned to the laboratory for confirmation of the pathogen. In brief, roots were surface disinfested with $10 \%$ bleach ( $0.62 \%$ sodium hypochlorite) and rinsed in sterile $\mathrm{ddH}_{2} \mathrm{O}$. Three small sections were plated onto UCV8 agar amended with 100 ppm ridomil and $100 \mathrm{ppm}$ ampicillin. The pathogen was confirmed from symptomatic tissue using morphological characteristics.

At the end of the study, plants that were not completely wilted (disease rating $\leq 4$ ) were returned to the laboratory for phenotypic evaluations to determine the effect of $P$. capsici infection on plant growth and root health. Plants were measured for final height, total fruit yield, and root health. Roots were thoroughly rinsed and rated using the following scale: $0=$ no symptoms, $1=$ small lesions on side roots only, 2 = small lesions on side root or small lesions on main root, $3=$ moder- ately sized lesions on main root, $4=$ large lesions on main root (Fig. 1). Total number of plants evaluated for plant traits and root health for each accession varied as not all plants for resistant/semiresistant lines survived to the end of the study. The experiment was conducted two times for each line and isolate.

Genetic diversity and population structure. Using previously published marker SSR data for the 77 of the 81 individuals evaluated in this study, genetic diversity and population structure were evaluated (Naegele et al., 2014). Genetic population indices based on continent were calculated using 23 markers in Poppr (Kamvar et al., 2014) within R (v3.5.1) statistical software (R Core Team, 2019) including number of observed and expected MLG (genotypic richness), rarefaction statistics, genotypic abundance of MLG diversity [Shannon-Wiener Index 
(H)] (Shannon, 2001), Simpsons index $(\lambda)$ (Simpson, 1949), Nei's unbiased gene diversity $\left(\mathrm{H}_{\exp }\right)(\mathrm{Nei}, 1978)$, and the linkage disequilibrium [index of association $\left(\mathrm{I}_{\mathrm{A}}\right)$ ] (Brown et al., 1980) (Tables 2 and 3). G was calculated using Poppr (Kamvar et al., 2014).

Using the software GenAlEx 6.05 (Peakall and Smouse, 2012), analyses of molecular variance (AMOVA) among and between populations based on continent (North America, South America, Europe, Africa, and Asia) and root rot resistance (R, MR, MS, and S) frequencies were calculated and significance determined (based on 999 permutations). Because only a single pepper genotype was resistant to isolate 12889, AMOVA was run using categories for resistant/moderately resistant, moderately susceptible, and susceptible individuals, only. For plants with differential reactions between the two experimental runs, the highest disease susceptibility rating was used for analyses. Population differentiation was tested for statistical signifi-

Table 2. SSR-based markers evaluated against a diverse panel of Capsicum annuum lines.

\begin{tabular}{lcccc}
\hline Locus & No Alleles & $1-\mathrm{D}^{\mathrm{y}}$ & $\mathrm{H}_{\text {exp }}{ }^{\mathrm{x}}$ & Evenness $^{\mathrm{w}}$ \\
\hline P1-1 & 4 & 0.49 & 0.49 & 0.69 \\
P1-19 & 3 & 0.57 & 0.57 & 0.81 \\
P1-20 & 3 & 0.22 & 0.22 & 0.49 \\
P1-21 & 4 & 0.25 & 0.25 & 0.51 \\
P1-26 & 4 & 0.59 & 0.60 & 0.76 \\
P1-43 & 2 & 0.27 & 0.28 & 0.67 \\
P1-47 & 2 & 0.34 & 0.34 & 0.75 \\
P2-8 & 3 & 0.49 & 0.49 & 0.72 \\
P2-10 & 3 & 0.45 & 0.45 & 0.68 \\
P2-29 & 3 & 0.56 & 0.56 & 0.86 \\
P2-42 & 4 & 0.23 & 0.23 & 0.50 \\
P2-43 & 5 & 0.58 & 0.58 & 0.62 \\
P2-46 & 4 & 0.28 & 0.28 & 0.52 \\
P3-1 & 4 & 0.17 & 0.17 & 0.43 \\
P3-3 & 3 & 0.42 & 0.43 & 0.65 \\
P3-7 & 5 & 0.63 & 0.63 & 0.79 \\
P3-11 & 3 & 0.34 & 0.34 & 0.60 \\
P3-16 & 2 & 0.10 & 0.10 & 0.49 \\
P3-17 & 2 & 0.11 & 0.12 & 0.50 \\
P4-11 & 6 & 0.69 & 0.70 & 0.77 \\
P4-19 & 4 & 0.50 & 0.50 & 0.76 \\
P4-21 & 7 & 0.67 & 0.67 & 0.66 \\
P4-43 & 6 & 0.74 & 0.75 & 0.82 \\
Mean & 3.74 & 0.42 & 0.42 & 0.65 \\
\hline P & &
\end{tabular}

${ }^{\mathrm{z}}$ Number of alleles distinguished by each marker.

${ }^{\mathrm{y}}$ Simpson index.

${ }^{\mathrm{x}}$ Nei's unbiased gene diversity (Nei, 1978).

${ }^{\mathrm{w}}$ Distribution of alleles.

Table 3. Population summary statistics for Capsicum annuum lines evaluated for Phytophthora capsici resistance grouped by continent of origin.

\begin{tabular}{lccccr}
\hline Population & $\mathrm{N} \mathrm{Obs}^{\mathrm{z}}$ & $\mathrm{H}^{\mathrm{y}}$ & Lambda $^{\mathrm{x}}$ & $\mathrm{H}_{\text {exp }}{ }^{\mathrm{w}}$ & rbarD $^{\mathrm{v}}$ \\
\hline Africa & 4 & 1.39 & 0.750 & 0.339 & 0.8809 \\
Asia & 24 & 3.18 & 0.958 & 0.428 & 0.00224 \\
Europe & 16 & 2.77 & 0.938 & 0.379 & -0.00705 \\
North America & 12 & 2.48 & 0.917 & 0.393 & -0.02041 \\
South America & 21 & 3.04 & 0.952 & 0.430 & 0.01581 \\
Total & 77 & 4.34 & 0.987 & 0.424 & 0.00293 \\
\hline
\end{tabular}

${ }^{\mathrm{z}}$ No. of observed samples.

${ }^{\mathrm{y}}$ Shannon-Wiener Index of Multi Locus Genotypes diversity.

'Simpson's index.

wNei's unbiased gene diversity (Nei, 1978).

${ }^{\mathrm{v}}$ Standardized index of association.

cance (based on the mean and $95 \%$ confidence interval). Genetic differentiation $\left(\mathrm{F}_{\mathrm{ST}}\right)$ among subpopulations was classified as little, moderate, great, and very great as described by Wright (1978) and implemented by Hartl and Clark (2007).

Population structure was estimated using STRUCTURE v2.3 (Pritchard et al., 2000) and $k$ (number of subpopulations present) was determined by the log likelihood difference as described by Evanno et al. (2005) using STRUCTURE Harvester (Earl and Vanholdt, 2012). In brief, a single population was used to determine lambda for subsequent testing. A total of $15 \mathrm{k}$-values were tested in STRUCTURE using the admixed model with independent allele frequencies (Falush et al., 2003). Each $\mathrm{k}$ value was tested with a burn in of 100,000 Markov Chain Monte Carlo (MCMC) and 500,000 replicate MCMC a lambda of 0.6459 , and five independent runs. Individuals were assigned to a cluster based on the estimated proportion ( $\geq 60 \%$ ) of membership (Q). Individuals that could not be assigned to a cluster were considered admixed. Clusters were visualized by category (disease resistance, region, and country of origin) using a population sorting script implemented in $\mathrm{R}$ (DeLong et al., 2020).

Statistical analyses. Area under the disease progress curve (AUDPC) values were calculated for each line as described by Shaner and Finney (1977). To account for batch differences, disease values were reported as a proportion of the AUDPC for each line compared with the susceptible control (Grif 9094) in the batch. All statistical analyses were performed in SAS v. 9.3 (SAS Institute, Cary, NC). Data were analyzing using analysis of variance implemented within the PROC MIXED function. Line, isolate, and interaction means were separated using least significant differences at $P=0.05$, when significant. When analyzing unequal sample sizes, degrees of freedom were accounted using the Kenward-Roger option implemented in SAS. Root rot resistance was classified as resistant ( 0.0 to 0.1$)$, moderately resistant $(>0.10$ to 0.25$)$, moderately susceptible $(>0.25$ to 0.50$)$, and susceptible $(>0.50)$ based on the final AUDPC proportion. Previously published fruit rot data on the same population using the same two isolates OP97 and 12889 were compared with root rot results (Naegele et al., 2015). Correlations were assessed using the Pearson's correlation coefficient $(r)$ with the PROC CORR function.

\section{Results}

Root rot evaluations. Significant differences were observed in disease susceptibility among pepper lines when inoculated with isolate OP97 or 12889. Control plants exhibited no wilting symptoms, and no $P$. capsici was isolated from the roots. Across the different batches, CM334 had an AUDPC ranging from 0 to 27.8 and Grif 9094 had an average AUDPC of 155.4 to 239. The pathogen was confirmed from inoculated plants with symptomatic tissue. There were significant differences between the two repetitions of the experiment $(P=0.0009)$, and data from each were analyzed separately. Pepper line was significant in each replicate $(P<0.0001)$. In the first experiment, isolate was not significant $(P=0.52)$, but the interaction between line and isolate was significant $(P=$ 0.0037 ). Most of the lines were either not significantly less resistant compared with the resistant (34) or less susceptible compared with the susceptible control (42) pepper line when inoculated with isolate 12889 . Five lines were significantly different with an intermediate rating from both the resistant and susceptible control when inoculated with isolate 12889 . However, only CM334 was classified as resistant, not moderately resistant, in both experiments. Other sources of resistance (PI 201232, PI 201234, PI 201237, PI 224438, PI 511884, PI 566811, and PI 593493) were resistant or moderately resistant in both experiments when inoculated with isolate 12889 . When inoculated with isolate OP97, 26 and 45 lines were not significantly more resistant or susceptible than the resistant control or susceptible controls, respectively. Ten lines were significantly different with an intermediate rating from both the resistant and susceptible controls when inoculated with isolate OP97.

In the second experiment, isolate 12889 was more virulent than OP97 $(P<0.0001)$, but the interaction between line and isolate was not significant $(P=0.5562)$. Sixty-two lines were not significantly less or more susceptible than the susceptible control Grif 9094 when inoculated with isolate 12889 . Twenty lines were not significantly more or less resistant than the resistant control CM334 (isolate 12889). Two lines displayed an intermediate rating that were not significantly different from either the susceptible or resistant control when inoculated with isolate 12889. When inoculated with isolate OP97, most pepper lines were not significantly more or less resistant compared with the resistant (35) control or more or less susceptible (50) than the susceptible control. Three lines had an intermediate rating and were not significantly different from both the resistant and susceptible control (isolate OP97). Only pepper lines CM334, PI 201232, PI 201237, PI 201234, PI 201237, PI 201239, PI 224438, PI 511844, PI 566811, PI 593573, and Early Jalapeno were consistently resistant/moderately 
Table 4. Analysis of molecular variance for pepper germplasm grouped by continent, resistance phenotype to isolate OP97, and STRUCTURE designated cluster.

\begin{tabular}{|c|c|c|c|c|c|c|}
\hline Grouping & Source ${ }^{z}$ & $\mathrm{df}^{\mathrm{y}}$ & $\mathrm{SS}^{\mathrm{x}}$ & $\mathrm{MS}^{\mathrm{w}}$ & Est Varv & $\%^{u}$ \\
\hline \multirow[t]{3}{*}{12889} & Among pop & 2 & 10.863 & 5.432 & 0.033 & 1 \\
\hline & Within ind & 77 & 148.000 & 1.922 & 1.922 & 59 \\
\hline & Total & 153 & 497.786 & & 3.285 & 100 \\
\hline \multirow{3}{*}{ OP97 } & Among ind & 73 & 702.786 & 9.627 & 4.090 & 71 \\
\hline & Within ind & 77 & 111.500 & 1.448 & 1.448 & 25 \\
\hline & Total & 153 & 859.344 & & 5.759 & 100 \\
\hline \multirow{2}{*}{ Continent } & Within ind & 77 & 111.500 & 1.448 & 1.448 & 25 \\
\hline & Total & 153 & 860.045 & & 5.740 & 100 \\
\hline \multirow[t]{4}{*}{ Cluster } & Among pop & 5 & 133.283 & 26.657 & 0.738 & 13 \\
\hline & Among ind & 71 & 615.210 & 8.665 & 3.608 & 62 \\
\hline & Within ind & 77 & 111.500 & 1.448 & 1.448 & 25 \\
\hline & Total & 153 & 859.994 & & 5.795 & 100 \\
\hline
\end{tabular}

${ }^{{ }^{Z}}$ Source of variation among populations (among pop), among individuals (among ind), within individuals (within ind), or the total population (total).

${ }^{\mathrm{y}}$ Degrees of freedom for each of the sources of variation.

${ }^{\mathrm{x}}$ Sum of squares.

${ }^{\mathrm{w}}$ Expected mean of squares.

Estimated variation.

"Percentage of the total variation explained.

resistant to $P$. capsici across both isolates and both experiments. Fifteen pepper lines displayed differential responses from moderately resistant/resistant to moderately susceptible/ susceptible across experimental replicates to one or both isolates.

Trait evaluation of surviving plants. Only 20 lines consistently (in both experiments) had three to four surviving plants at the end of the study for a given experiment. No consistent differences were detected among control or inoculated plants in plant height in resistant or partially resistant plants that survived until the end of the study for any of the genotypes evaluated. For root rot visual ratings of the surviving plants, significant negative differences between the control and surviving inoculated plants were detected for partially resistant pepper lines: PI 640803, PI 631140, and PI 640461. Each of these genotypes showed differential responses for wilting between experiments for isolates 12889 or OP97. For the remaining partially resistant genotypes, no significant differences in root lesions were detected among inoculated and millet inoculated control plants compared with CM334.

Fruit rot correlation with root rot. When fruit rot and root rot resistance were compared, fruit rot resistance had a significant positive correlation with root rot resistance for both isolates. Root rot resistance to isolate 12889 had a small positive correlation with fruit rot resistance to the same isolate at $3 \mathrm{~d}$ postinoculation (dpi) $(r=0.35051, P=$ $0.0017 ; r=0.26493, P=0.0191$ for round 1 and round 2 of the experiment, respectively). A stronger correlation between root rot and fruit rot resistance at $5 \mathrm{dpi}$ was observed when inoculated with isolate $12889(r=$ $0.49894, P<0.0001 ; r=0.41823, P=$ 0.0001 for round 1 and round 2 of the experiment, respectively). When inoculated with isolate OP97, root rot resistance and fruit rot resistance had a stronger positive correlation 5 dpi $(r=0.63499, P<0.0001 ; r=0.46392$,
$P<0.0001)$ compared with 3 dpi $(r=0.46628$, $P<0.0001 ; r=0.39461, P=0.0004)$ for both round 1 and round 2 of the experiment, respectively). Pepper line PI 566811 was the only accession evaluated with moderate resistance to fruit rot five dpi and root rot to both isolates of $P$. capsici in both experiments.

Genetic diversity and population structure. Of the 23 markers evaluated, genetic diversity (Nei, 1978) ranged from 0.15 to 0.78 . Evenness for SSR markers ranged from 0.45 to 0.80 . The mean genetic diversity and evenness for the population was 0.42 and 0.65 , respectively. The adjusted index of association (rbarD) was low for the population, indicating frequent recombination based on the 23 markers (Table 2). Genotype accumulation curves indicated that detected genotypic differences for the population reached saturation with only 13 of the 23 loci evaluated (Supplemental Fig. 1). Global $\mathrm{G}_{\mathrm{ST}}$ was 0.0804 . Using AMOVA most of the variation observed was within populations, and not among populations, when grouped by continent and disease resistance for OP97 (Table 4). Significance for each of the groupings was $P=0.001$. AMOVA values for disease resistance (resistant/ moderately resistant, moderately susceptible, and susceptible) to isolate 12889 were not significant $(P=0.052)$. The percentage of molecular variance among populations was $6 \%, 1 \%$, and $4 \%$ when grouped by continent, resistance to isolate 12889, and resistance to isolate OP97, respectively.

For STRUCTURE analysis, a k value of 5 was selected, and individuals were assigned to their respective clusters. Low admixture was detected because most individuals were able to be assigned to a single cluster. When grouped by cluster, $13 \%$ of the variation was among clusters based on AMOVA, $P=0.001$ (Table 4). Cluster 3 (light blue) had the fewest individuals (8), and cluster 4 (dark blue) had the most (23). Cluster 1 (dark purple), cluster 2 (yellow), and cluster 5 (light purple) and 15, 18, and 9 individuals, respectively. Only 4 individuals could not be placed into a cluster and were considered admixed, designated as cluster 6 (Table 1).

Clustering individuals by resistance level to OP97 or 12889 indicated that no clusters were solely present in the resistant/moderately resistant clusters and not the moderately susceptible/susceptible categories. The exception to this was individuals with $60 \%$ membership in the dark purple cluster, which was present only in the susceptible category. The light blue and light purple clusters were present in a higher proportion in the resistant/ moderately resistant categories compared in the moderately susceptible/susceptible categories. However, individuals with a majority membership from the yellow and dark blue clusters were also present in the resistant/ moderately resistant categories.

When grouped by continent, Europe had no representation of the yellow cluster (2) and a greater than expected representation of the dark purple cluster (1). Light purple and light blue, which were present in higher proportions in the resistant/moderately resistant categories, were found primarily samples from Asia and North America.

\section{Discussion}

In this study, we evaluated diverse pepper lines for resistance to Phytophthora root rot and compared their resistance to previously published fruit rot using the same two isolates (Naegele et al., 2014). CM334 was consistently resistant to both isolates across both experiments consistent with previous studies identifying it as a broad spectrum source of root rot resistance to $P$. capsici (Glosier et al., 2008; Mallard et al., 2013). Most, though not all, of the material we evaluated had previously been tested for root rot resistance using a mixed set of six isolates (Candole et al., 
2010). While most of the accessions behaved as expected, eight (PIs 201239, 263077, 369996, 427290, 511879, 555649, 631147, and 640532) that had previously been reported as moderately resistant (e.g., survived to fruit set) were susceptible to one or both of the isolates we evaluated in one or both of the experiments.

Many pepper lines were consistently susceptible or R/MR to $P$. capsici across both experiments, however some lines showed variability suggesting an environmental, as well as an isolate-specific, component to resistance. This was evidenced by pepper lines PI 640803, PI 631140, and PI 640461 that exhibited differential disease susceptibility responses. These lines had high variability in disease response between the first and second experiment for isolate 12889 , but not OP97, and at the end of the experiment exhibited large root lesions. Lines PI 640803 in the study by Candole et al. (2010) exhibited high susceptibility to $P$. capsici; however PI 640461 had $>70 \%$ survival with an average root rot severity of 1 to 2 .

Isolate-specific interactions are well known, and our results highlight the importance of confirming host resistance using local $P$. capsici populations. Candole et al. (2010) used a mixed set of isolates from Georgia when evaluating for resistance. Of the 75 accessions that we evaluated in common, eight displayed a differential resistance response between the two isolates. Although these accessions may not be useful sources of broad spectrum resistance, they could harbor unique isolate-specific alleles that could bolster the major resistance locus found in CM334 on chromosome 5. One potential accession, PI 566811, a local cultivar from Mexico, had moderate consistent resistance to root and fruit rot to both isolates evaluated.

Fruit rot resistance, although not important in all pepper production systems, should still be considered when breeding resistant peppers. When fruit rot resistance was compared with root rot resistance, there was a moderate positive correlation between the two for both of the isolates evaluated, particularly $5 \mathrm{~d}$ postinoculation, across the population. Although correlated, fruit rot resistance and root rot resistance were not strong predictors of each other, and both should still be evaluated when possible. Pepper accession CM334 has broad spectrum root rot resistance to $P$. capsici but had greater fruit rot than accession PI 566811 that only had moderate root rot resistance. This is consistent with previous work that found a major qtl on chromosome 5 was associated with fruit rot resistance but also identified qtl on chromosomes 2, 3, 4, and 6 associated with fruit rot in a small biparental mapping population (Naegele et al., 2013). The significant correlation between fruit rot and root rot is likely the result of a shared major qtl on chromosome 5, with smaller effect unique qtl on chromosomes 2 and 4 possibly being fruit rot resistance specific. Fruit rot and root rot resistance correlations also were affected by isolate, with isolate
12889 , previously reported as highly virulent, having a weaker correlation than isolate OP97.

Studies evaluating the population structure of pepper have found regional and global structure (Aguilar-Melendez et al., 2009; Hernández-Verdugo et al., 2001; Hill et al., 2013; Oyama et al., 2006; Pereira-Dias et al., 2019). In our study, five clusters (k) were determined to be the most likely, with low levels of admixture, which differed from the four clusters that were identified when all 157 accessions were included (Naegele et al., 2015). This is consistent with results from Pereira-Dias et al. (2019), who identified five clusters when evaluating a collection of 122 $C$. annuum using more than 4000 single nucleotide polymorphisms, and with results by Hill et al. (2013), who identified six clusters with low levels of admixture.

Numerous studies have identified or mapped resistance to $P$. capsici-incited rot in peppers (Mallard et al., 2013; Naegele et al., 2013; Thabuis et al., 2003). While chromosome 5 has a major qtl associated with $P$. capsici resistance, two other pepper genotypes examined had minor qtl on chromosomes 3, 6, 10, and 12 (Mallard et al., 2013). Using pepper germplasm with isolatespecific or partial resistance could help to identify additional unique loci or alleles for bolstering the resistance on chromosome 5 . When assigned to genetic clusters, resistant/ moderately resistant individuals were identified in the yellow, light blue, light purple, and dark blue clusters. These clusters were distributed across continents, but the light purple and light blue clusters had a higher frequency in North America (specifically Mexico) and Asia. This was further supported by the AMOVA, which showed a significant separation among continents, clusters, and disease-resistance phenotypes for isolate OP97. These individuals with moderately resistant or resistant phenotypes to both isolates and representing different genetic clusters could be useful targets for identifying divergent resistance loci for breeding Phytophthora-resistant peppers. Further studies to evaluate the inheritance and position of resistance loci are needed to confirm the usefulness of these materials for enhancing disease resistance.

Phytophthora capsici-incited rot of pepper is a significant production challenge, and breeding new cultivars with durable resistance is paramount for developing a sustainable management program. Although many studies have identified sources of resistance to $P$. capsici in pepper, our results highlight the importance of using diverse isolates with known virulence variability to evaluate host resistance and identify targets for breeding with unique resistance loci.

\section{Literature Cited}

Aguilar-Melendez, A., P.L. Morrell, M.L. Roose, and S.C. Kim. 2009. Genetic diversity and structure in semiwild and domesticated chiles (Capsicum annuum; Solanaceae) from Mexico. Amer. J. Bot. 96:1190-1202.
Barksdale, T.H. 1984. Resistance to foliar blight and crown rot of pepper caused by Phytophthora capsici. Plant Dis. 68:506.

Biles, C.L. 1993. Relationship of Phytophthora fruit rot to fruit maturation and cuticle thickness of New Mexican-type peppers. Phytopathology 83:607.

Brown, A.H.D., M.W. Feldman, and E. Nevo. 1980. Multilocus structure of natural populations of Hordeum spontaneum. Genetics 96:523-536.

Candole, B.L. 2012. Evaluation of Phytophthora root rot-resistant (Capsicum annuum) accessions for resistance to Phytophthora foliar blight and Phytophthora stem blight. Agr. Sci. 03:732-737.

Candole, B.L., P.J. Conner, and P. Ji. 2010. Screening Capsicum annuum accessions for resistance to six isolates of Phytophthora capsici. HortScience 45:254-259.

Castro-Rocha, A., S. Shrestha, B. Lyon, G.L. Grimaldo-Pantoja, J.P. Flores-Marges, J. ValeroGalván, M. Aguirre-Ramirez, P. Osuna-Avila, N. Gomez-Dorantes, G. Avila-Quezada, J. de Jesus Luna-Ruiz, G. Rodriguez-Alvarado, S.P. Fernandez -Pavia, and K. Lamour. 2016. An initial assessment of genetic diversity for Phytophthora capsici in northern and central Mexico. Mycol. Prog. 15:15.

DeLong, J., S. Saito, C.L. Xiao, and R.P. Naegele. 2020. Population genetics and fungicide resistance of Botrytis cinerea on Vitis and Prunus spp. in California. Phytopathology 110:694 702.

Earl, D.A. and B.M. vonHoldt. 2012. STRUCTURE HARVESTER: A website program for visualizing STRUCTURE output and implementing the Evanno method. Conserv. Genet. Resour. 4:359-361.

Enzenbacher, T.B., R.P. Naegele, and M.K. Hausbeck. 2015. Susceptibility of greenhouse ornamentals to Phytophthora capsici and $P$. tropicalis. Plant Dis. 99:1808-1815.

Evanno, G., S. Regnaut, and J. Goudet. 2005. Detecting the number of clusters of individuals using the software STRUCTURE: A simulation study. Mol. Ecol. 14:2611-2620.

Falush, D., M. Stephens, and J.K. Pritchard. 2003. Inference of population structure: Extensions to linked loci and correlated allele frequencies. Genetics 164:1567-1587.

Foster, J.M. and M.K. Hausbeck. 2010. Resistance of pepper to Phytophthora crown, root, and fruit rot is affected by isolate virulence. Plant Dis. 94:24-30.

Foster, J.M., R.P. Naegele, and M.K. Hausbeck. 2012. Evaluation of eggplant rootstocks and pepper varieties for potential resistance to isolates of Phytophthora capsici from Michigan and New York. Plant Dis. 97:1037-1041.

Gilardi, G., M. Baudino, M. Moizio, M. Pugliese, A. Garibaldi, and M.L. Gullino. 2013. Integrated management of Phytophthora capsici on bell pepper by combining grafting and compost treatment. Crop Prot. 53:13-19.

Glosier, B.R., E.A. Ogundiwin, G.S. Sidhu, D.R. Sischo, and J.P. Prince. 2008. A differential series of pepper (Capsicum annuum) lines delineates fourteen physiological races of Phytophthora capsici. Euphytica 162:23-30.

Granke, L.L., L.M. Quesada-Ocampo, and M.K. Hausbeck. 2012a. Differences in virulence of Phytophthora capsici isolates from a worldwide collection on host fruits. Eur. J. Plant Pathol. 132:281-296.

Granke, L.L., L.M. Quesada-Ocampo, K. Lamour, and M.K. Hausbeck. 2012b. Advances in research on Phytophthora capsici on Vegetable 
Crops in The United States. Plant Dis. 96:1588-1600.

Hartl, D.L. and A.G. Clark. 2007. Principles of population genetics. 4th ed. Sinauer Associates, Inc., Sunderland, MA.

Hernández-Verdugo, S., R. Luna-Reyes, and K. Oyama. 2001. Genetic structure and differentiation of wild and domesticated populations of Capsicum annuum (Solanaceae) from Mexico. Plant Syst. Evol. 226:129-142.

Hill, T.A., H. Ashrafi, S. Reyes-Chin-Wo, J. Yao, K. Stoffel, M.J. Truco, A. Kozik, R.W. Michelmore, and A. Van Deynze. 2013. Characterization of Capsicum annuum genetic diversity and population structure based on parallel polymorphism discovery with a $30 \mathrm{~K}$ unigene Pepper GeneChip. PLoS One 8:e56200.

Kamvar, Z.N., J.F. Tabima, and N.J. Grunwald. 2014. Poppr: an R package for genetic analysis of populations with clonal, partially clonal, and/or sexual reproduction. PeerJ 2e:281, doi: 10.7717/peerj.281.

Lamour, K.H. and M.K. Hausbeck. 2001. Investigating the spatiotemporal genetic structure of Phytophthora capsici in Michigan. Phytopathology 91:973-980.

Lamour, K.H. and M.K. Hausbeck. 2000. Mefenoxam insensitivity and the sexual stage of Phytophthora capsici in Michigan cucurbit fields. Phytopathology 90:396-400.

Lefebvre, V. and A. Palloix. 1996. Both epistatic and additive effects of QTLs are involved in polygenic induced resistance to disease: A case study, the interaction pepper - Phytophthora capsici Leonian. Theor. Appl. Genet. 93:503511.

Mallard, S., M. Cantet, A. Massire, A. Bachellez, S. Ewert, and V. Lefebvre. 2013. A key QTL cluster is conserved among accessions and exhibits broad-spectrum resistance to Phytophthora capsici: A valuable locus for pepper breeding. Mol. Breed. 32:349-364.

Naegele, R., T. Hill, H. Ashrafi, S. Reyes Chin-Wo, A. Van Deynze, and M.K. Hausbeck. 2013. QTL mapping of fruit rot resistance to the plant pathogen Phytophthora capsici Leonian in a recombinant inbred line Capsicum annuum $\mathrm{L}$. population. Phytopathology 104:479-483.

Naegele, R.P., S. Boyle, L.M. Quesada-Ocampo, and M.K. Hausbeck. 2014. Genetic diversity, population structure, and resistance to Phytophthora capsici of a worldwide collection of eggplant germplasm. PLoS One 9:e95930.

Naegele, R.P., A.J. Tomlinson, and M.K. Hausbeck. 2015. Evaluation of a diverse, worldwide collection of wild, cultivated, and landrace pepper (Capsicum annuum) for resistance to phytophthora fruit rot, genetic diversity, and population structure. Phytopathology 105:110118.

Nei, M. 1978. Estimation of average heterozygosity and genetic distance from a small number of individuals. Genetics 89:583-590.

Oelke, L.M., P.W. Bosland, and R. Steiner. 2003. Differentiation of race specific resistance to Phytophthora root rot and foliar blight in Capsicum annuиm. J. Amer. Soc. Hort. Sci. 128:213-218.

Ortega, R.G., C.P. Español, and J.C. Zueco. 1991. Genetics of resistance to Phytophthora capsici in the pepper line 'SCM-334'. Plant Breed. 107:50-55.

Oyama, K., S. Hernández-Verdugo, C. Sánchez, A. González-Rodríguez, P. Sánchez-Peña, J.A. Garzón-Tiznado, and A. Casas. 2006. Genetic structure of wild and domesticated populations of Capsicum annuum (Solanaceae) from northwestern Mexico analyzed by RAPDs. Genet. Resources Crop Evol. 53:553-562.

Parada-Rojas, C. and L.M. Quesada-Ocampo. 2019. Characterizing sources of resistance to Phytophthora blight of pepper caused by Phytophthora capsici in North Carolina. Plant Health Prog. 20:112-119.

Peakall, R. and P.E. Smouse. 2012. GenAlEx 6.5: Genetic analysis in Excel. Population genetic software for teaching and research-An update. Bioinformatics 28:2537-2539.

Pereira-Dias, L., S. Vilanova, A. Fita, J. Prohens, and A. Rodríguez-Burruezo. 2019. Genetic diversity, population structure, and relationships in a collection of pepper (Capsicum spp.) landraces from the Spanish centre of diversity revealed by genotyping-by-sequencing (GBS). Hort. Res. 6:1-13.

Pritchard, J.K., M. Stephens, and P. Donnelly. 2000. Inference of population structure using multilocus genotype data. Genetics 155:945-959.

Quesada-Ocampo, L.M., L.L. Granke, M.R. Mercier, J. Olsen, and M.K. Hausbeck. 2011.
Investigating the genetic structure of Phytophthora capsici populations. Phytopathology 101:1061-1073.

Quesada-Ocampo, L.M. and M.K. Hausbeck. 2010. Resistance in tomato and wild relatives to crown and root rot caused by Phytophthora capsici. Phytopathology 100:619-627.

R Core Team. 2019. R: A language and environment for statistical computer. R Foundation for Statistical Computing. Vienna, Austria. $<$ https://www.R-project.org $>$.

Saini, S.S. and P.P. Sharma. 1978. Inheritance of resistance to fruit rot (Phytophthora capsici Leon.) and induction of resistance in bell pepper (Capsicum annuum L.). Euphytica 27:721723.

Shaner, G. and R.E. Finney. 1977. The effect of nitrogen fertilization on the expression of slowmildewing resistance in Knox wheat. Phytopathology 67:1051-1056.

Shannon, C.E. 2001. A mathematical theory of communication. ACM SIGMOBILE Mob. Comput. Commun. Rev. 5:3-55.

Simpson, E. 1949. Measurement of diversity. Nature 163:688.

Sy, O., P.W. Bosland, and R. Steiner. 2005. Inheritance of Phytophthora stem blight resistance as compared to Phytophthora root rot and Phytophthora foliar blight resistance in Capsicum annuum L. J. Amer. Soc. Hort. Sci. 130:75-78.

Sy, O., R. Steiner, and P.W. Bosland. 2008. Recombinant inbred line differential identifies race-specific resistance to Phytophthora root rot in Capsicum annuum. Phytopathology 98:867-870.

Tahboub, M.B., S. Sanogo, P.W. Bosland, and L. Murray. 2008. Heat level in chile pepper in relation to root and fruit infection by Phytophthora capsici. HortScience 43:1846-1851.

Thabuis, A., A. Palloix, S. Pflieger, A.M. Daubeze, C. Caranta, and V. Lefebvre. 2003. Comparative mapping of Phytophthora resistance loci in pepper germplasm: Evidence for conserved resistance loci across Solanaceae and for a large genetic diversity. Theor. Appl. Genet. 106:1473-1485.

Wright, S. 1978. Evolution and genetics of populations. Vol 4. Variability within and among natural populations. University of Chicago Press, Chicago, IL. 


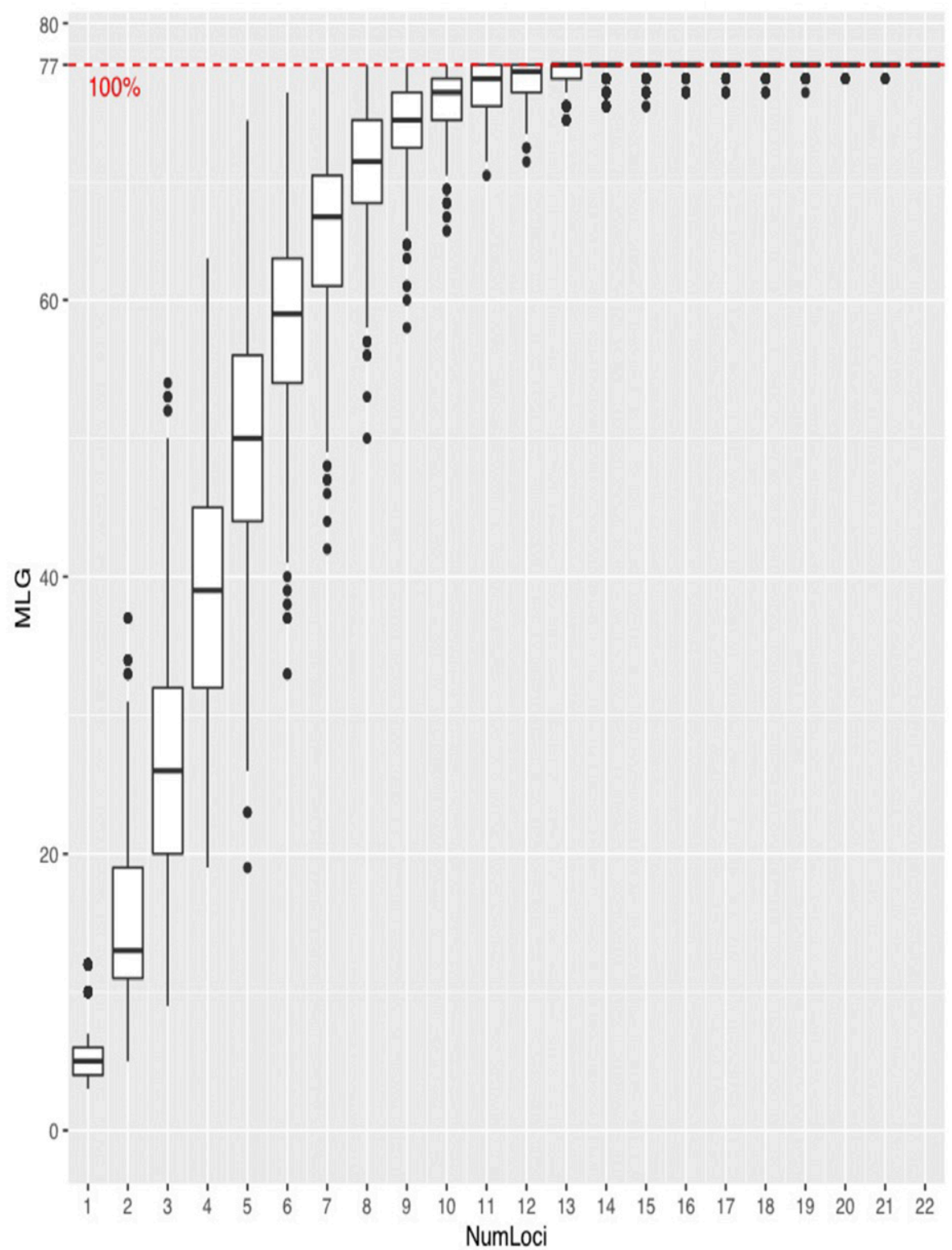

Supplemental Fig. 1. Genotype accumulation curve for pepper germplasm evaluated using SSR markers. 